\title{
EN EL PAÍS DE LOS FANTASMAS SIN NOMBRE: GUERRA INTERNA, ESTADO TOTALITARIO Y DUELO NACIONAL EN LOST CITY RADIO DE DANIEL ALARCÓN
}

\author{
POR \\ Luis H. CASTAÑEDA \\ Middlebury College
}

Lost City Radio(2007), ${ }^{1}$ la primera novela del escritorperuano-norteamericano Daniel Alarcón (Lima, 1977), pone en escena un universo ficcional distópico en el que algunos críticos han localizado una reelaboración de realidades socio-políticas latinoamericanas contemporáneas, sin precisar referentes nacionales (Tonkin 2007). Otros han señalado, como referente específico, el Perú de las últimas dos décadas del siglo xx, marcado por la guerra interna entre el estado y el grupo terrorista Sendero Luminoso, y la posterior instalación del gobierno autoritario de Alberto Fujimori (Faverón 2007). Dicho eso, se debe acotar que una diferencia clave entre el Estado peruano de la década de los 90 y el Estado representado en Lost City Radio está en el nivel de penetración del poder estatal en la vida pública y privada de los ciudadanos. En la novela, siguiendo la línea de la tradición distópica europea, encontramos un Estado omnipotente que ejerce un control total sobre la vida social. Por el contrario, el gobierno de Alberto Fujimori oscila entre las categorías de "democracia parcial" y "régimen autoritario-electoral" (McClintock 245). Lo cierto es que Lost City Radio narra dos décadas en la vida política de una nación sudamericana imaginaria cuyo nombre es, significativamente, omitido. La primera década corresponde al sangriento conflicto armado con el grupo subversivo IL ("Illegitimate Legion"), mientras que el periodo de la posguerra involucra las secuelas traumáticas de la violencia en una sociedad civil oprimida por un régimen totalitario. Estas analogías existentes entre el mundo ficcional y la historia reciente del Perú permiten fijar cruces y semejanzas, lectura reforzada por otras coincidencias que se derivan de la geografía

\footnotetext{
El texto original fue escrito en inglés. Se publicó una traducción al español en 2007, el mismo año de la publicación del original: Radio ciudad perdida. El primer texto publicado por Alarcón es el libro de cuentos War By Candlelight (2005), que fue traducido al español como Guerra a la luz de las velas en 2006. En este libro, la mayoría de los cuentos están situados en el Perú y se desarrollan los temas de la marginalidad urbana, la violencia política de los 80-90, siguiendo los vectores de la filiación y la afiliación, -como en Lost City Radio-. Para un estudio sobre el motivo de la emigración en Guerra a la luz de las velas ver Yushimito 2006.
} 
de la nación ficcional. La más evidente reside en la división longitudinal del espacio natural, que se reparte gruesamente en tres regiones: la costa, la sierra y la selva, que corresponden a la tripartición tradicional del territorio del Perú. Adicionalmente, la centralización política de esta nación, en la cual la ciudad capital domina un espacio nacional relegado, parece corresponderse con la hipertrofia limeña, que ha reinado en el Perú durante su historia republicana.

Si se busca establecer un nexo entre la ficción de Alarcón y la realidad peruana, es necesario reconocer que dicho vínculo pasa por una representación distópica de la historia social y política del Perú. La distopía es un subgénero cuya característica básica es la proyección, en un tiempo futuro, de los males de la sociedad contemporánea (Davies 205). Según algunos críticos, la distopía ilumina irónicamente las imperfecciones que yacen al interior de los mundos idílicos de la utopía: la grieta intrínseca del pensamiento utópico vendría a ser su tendencia a desear estados centralizados y colectivistas, que terminan oprimiendo al individuo (Plattel 47; Richter 5-9). En Lost City Radio la opresión estata se hace objeto de reflexión; sin embargo, se trata de una distopía peculiar, ya que no está ambientada en el futuro. La nación imaginaria donde transcurre el argumento se esboza como una versión alternativa y extrañada del Perú, mientras que el tiempo representado corresponde a un pasado reciente en el cual es posible estudiar la construcción de la memoria colectiva.

La mímesis distópica oscurece el vínculo entre la realidad referencial -en este caso, la peruana-y su representación. Sin embargo, este oscurecimiento no implica que estemos ante una novela que abandone los predios del realismo, aunque la extrañeza que provoca en el lector pueda sugerirlo. Se debe recordar que el texto artístico de raigambre realista postula una ilusión de transparencia y continuidad entre el mundo representado y su referente-que Lukács denominó el reflejo objetivo de la realidad-, ${ }^{2}$ ilusión que se impone al lector en co-presencia, ineludiblemente paradójica, de su antítesis: la conciencia del artificio. La mímesis distópica de Alarcón parece funcionar, entonces, como una forma particular de realismo, porque si bien el referente peruano ha sido oscurecido, transfigurado y desplazado en el tiempo y el espacio, el texto sigue refiriéndose a él, comentándolo e interpretándolo, y cumpliendo por tanto el objetivo de la ficción realista. Así, ese espacio-tiempo distópico que sirve de comentario a la realidad peruana, está lejos de reclamar un estatus autotélico: lo cierto es que constituye un lugar crítico desde

Para Lukács, el realismo se define por el proyecto de ofrecerle al lector un reflejo objetivo de la realidad que entabla una relación paradójica con las percepciones previas que el lector posee de la realidad. Esta dialéctica entre la familiaridad y la extrañeza se explica por el hecho de que el reflejo generado po la obra artística es más exacto y completo que las percepciones del lector (21-22). El reflejo objetivo de la realidad no consiste en la reproducción de detalles particulares y efectos superficiales, sino en la representación totalizante de las leyes de la sociedad (23).

Revista Iberoamericana, Vol. LXXIX, Núms. 244-245, Julio-Diciembre 2013, 1123-1139 ISSN 0034-9631 (Impreso) ISSN 2154-4794 (Electrónico) el cual es posible explorar las “determinaciones objetivas esenciales” (Lukács 23) del referente que la novela interpela: el Perú de los años 80 y 90

Los textos narrativos peruanos que intentan representar este periodo de violencia política suelen dramatizar los problemas colectivos en términos de sus consecuencias en la vida cotidiana, de sus efectos en las personas y sus relaciones más íntimas: la filiación es el problema central. ${ }^{3}$ En esta misma línea, Lost City Radio pone de relieve las vinculaciones entre la cuestión nacional, la memoria colectiva y el trauma individual. En este artículo me detengo a estudiar un punto clave en la construcción del universo ficcional: la medular interpenetración entre el ámbito de la vida doméstica y el ámbito de la vida pública, entre la esfera de las relaciones amorosas y familiares, y la esfera de acción del Estado. En Lost City Radio, la peculiar lógica de filiación postraumática que rige las biografías y las historias familiares proporciona la clave para comprender la interacción entre el Estado y la ciudadanía, entre las instituciones disciplinarias y la memoria colectiva, en un contexto de violencia política y desigualdad social. Los afectos y la política se entretejen para construir una determinada imagen de nación cuyo carácter intentaré definir. Asimismo, hacia el final procuraré mostrar que la lógica que siguen estas interrelaciones presenta una conexión con el concepto de "alegoría", tal y como lo entiende Doris Sommer en Foundational Fictions. Las tribulaciones de la filiación entrañan una dramatización, al nivel de la vida individual y de la dimensión corporal, de un modo particular de relacionarse con el poder del Estado y con los otros ciudadanos en el marco de la comunidad nacional.

El argumento de la novela gira en torno al programa de radio que da su título al texto: "Lost City Radio" es el nombre de un show dominical conducido por Norma, la protagonista de la historia. El objetivo del programa es propiciar el reencuentro de personas extraviadas con sus familias, a través de las llamadas telefónicas de oyentes que buscan a sus seres queridos: "Have you come to the city? Are you alone, or more alone, than you expected to be? Have you lost touch with those whom you expected to find here? This show, my friends, is for you" (222). La desintegración familiar es el fenómeno social más preocupante en un país sacudido por la guerra y fracturado por el centralismo. El reclutamiento de soldados para el ejército, y la migración del campo a la ciudad, son dos factores que resquebrajan la unidad del núcleo familiar. Por este motivo, "Lost City Radio", que nació durante la guerra, es el programa más popular del país

La presencia de una filiación problemática es otro de los puntos de encuentro entre el mundo representado en la novela de Alarcón y la representación de los efectos de la violencia política en la sociedad peruana de posguerra que se ofrece en el corpus de cuentos que Gustavo Faverón reúne en su antología Todas las sangres: "Las fuerzas enfrentadas en la guerra fueron prontamente percibidas como elementos desarticuladores de la filiación natural: portadores del mensaje del fin de la historia, nada podían engendrar que no fuera destrucción, y su presencia invasiva en pueblos y hogares era la disrupción de toda normalidad genética [...] La afiliación senderista implica necesariamente la clausura de la filiación natural" (17).

Revista Iberoamericana, Vol. LXXIX, Núms. 244-245, Julio-Diciembre 2013, 1123-1139 ISSN 0034-9631 (Impreso) ISSN 2154-4794 (Electrónico) 
en los nuevos tiempos de paz. La voz de Norma constituye el punto de encuentro que canaliza un urgente deseo colectivo y promete una fantasía de reconstitución familiar para desaparecidos y los desplazados. Por todo ello, Norma es una estrella famosa a nivel nacional, apreciada y reverenciada por sus seguidores. A pesar de que su aspecto físico es un misterio para los radioescuchas, su voz está cargada de un enorme poder simbólico que la convierte en algo más que una figura pública reconocida: casi podría decirse que es un objeto sacralizado por las masas.

Notoriamente, al igual que muchos de sus fanáticos, también la famosa conductora es una víctima de la guerra interna, pues su esposo Rey desapareció sin dejar rastro justo antes del final del conflicto armado, diez años antes del presente de la historia. La pérdida de Rey afectó profundamente la vida de Norma, en la que desde entonces cohabitan la desesperanza y la ilusión de reencontrar a su marido. Profesor universitario y simpatizante de IL a espaldas de su esposa, Rey llevó durante años una doble vida. En el convivían el hombre de familia y el subversivo, el científico interesado en el estudio de la flora selvática y el colaborador de los sediciosos que viajaba a la selva, secretamente, para servir a la Legión como mensajero. Allá, en una alejada aldea llamada 1797 -después del conflicto, todos los pueblos y ciudades del país fueron rebautizados con númerosse involucra con una mujer llamada Adela, con la que tiene un hijo: Víctor. Descubierta su afiliación terrorista, Rey es asesinado por los militares, dato que Norma ignora a lo largo de toda la novela. También ignora que Víctor es hijo de su esposo. Será este niño quien, después de la muerte accidental de Adela, desencadene la acción principal de la trama: acompañado de su profesor Manau, Víctor viaja desde 1797 hasta la capital para buscar a Norma y entregarle una lista de pobladores desaparecidos con la intención de que ella lea sus nombres en "Lost City Radio". Al hallar en la lista el nombre de Rey, Norma empieza a descubrir las turbias vinculaciones de su esposo con la lucha armada, así como también su infidelidad con Adela.

El descubrimiento de Norma es una revelación moral y política. Más allá de una fugaz vinculación juvenil con IL que le valió un encierro breve en una prisión informal llamada "La luna", después del matrimonio Rey se presentó siempre ante su mujer como un ciudadano crítico del Estado, aunque sin afiliación partidaria ni vida política activa fingía ser, apenas, un profesor interesado en la política. Por cierto, la secreta identidad subversiva de Rey contrasta con la conducta pasiva que mantiene Norma ante el Estado. Después de todo, el programa radial que ella conduce es propagado por la única emisora oficial que sobrevive en la posguerra, y está plenamente alineado con las imposiciones de la censura, mecanismo central de un régimen de control de los medios de comunicación que hace recordar, en cierta medida, la experiencia peruana de los años 90 (Mauceri 58). En la ficción, la censura es parte de una gestión estatal de la memoria colectiva. En efecto, una vez terminada la guerra y derrotados los subversivos, el Estado victorioso resolvió negar de plano la existencia de IL, y difundir la versión de que se trató de un

Revista Iberoamericana, Vol. LXXIX, Núms. 244-245, Julio-Diciembre 2013, 1123-1139 ISSN 0034-9631 (Impreso) ISSN 2154-4794 (Electrónico) fraude, un invento, con la intención de borrar de la historia reciente todo rastro del grupo rebelde y del mismo conflicto armado. Siguiendo un patrón típico de la construcción de la memoria colectiva, un conjunto de eventos cruciales queda desplazado: "The "crucial event' is thought of as something to be neglected or even cancelled. Life must continue as if nothing had happened. People need only to regain the interrupted path, to find themselves once more" (Cavalli 173). En este mundo donde el olvido es ley, la nueva vida se edifica sobre la represión de un dolor latente, represión que no es el resultado de "las decisiones de una pluralidad de actores"(Cavalli 173), sino del cumplimiento de una orden vertical. Dentro de un discurso progresista y modernizador que busca reescribir la memoria nacional, tanto el recuerdo de la violencia como la existencia misma de los ciudadanos sospechosos de simpatizar con IL deben ser erradicados. ${ }^{4}$ Esta borradura se manifiesta en la prohibición de recordar y pronunciar ciertos nombres. Para que el periodo de insurgencia pueda ser olvidado, se impone una amnesia selectiva que impide mencionar siquiera los nombres de los personajes que han sido expulsados del recuerdo.

Uno de esos nombres es el de Rey. De esta manera, este personaje funciona como la sinécdoque de todo un sector de la población que acecha, espectralmente, desde un olvido creado por mandato estatal. Como es evidente, la prohibición de los nombres afecta directamente a un programa como "Lost City Radio". Aquellos que Norma lee y da a conocer son sólo los nombres lícitos, los que no resultan problemáticos para el gobierno. La reconstitución de las familias separadas por la guerra, objetivo básico de "Lost City Radio", tiene como barrera la imposibilidad de recordar y convocar los nombres de aquellos ciudadanos cuyas identidades el Estado desea eliminar, después de haber exterminado sus cuerpos (en colaboración, queda claro, con la Legión Ilegítima: ambos son responsables de sembrar la muerte y la devastación en el país). Se puede decir que la desintegración familiar forma parte de la nueva legalidad de la posguerra. Ciertamente, ella es también sintomática de una realidad social heterogénea y determinada por fuertes asimetrías socio-económicas entre lo urbano y lo rural, entre la capital y las provincias, entre la burguesía y los grupos desfavorecidos.

Como puede verse, Lost City Radio es una novela especialmente preocupada por explorar ciertos estilos de filiación a través de una compleja estructura de relaciones amorosas y familiares que descansa en similitudes y analogías. Estas similitudes y analogías conforman una red de círculos concéntricos que parte de los personajes protagónicos, incluye a los personajes secundarios y se expande simbólicamente hacia

\footnotetext{
La estrategia del olvido parece ser una práctica común en las naciones afectadas por hechos traumáticos (Marques, Paez, Serra 254). La otra estrategia de reconstrucción de la memoria colectiva después de eventos traumáticos, es la que Alessandro Cavalli llama "elaboración de la memoria" (Cavalli 174), proceso que sólo puede ser llevado a cabo mediante el diálogo entre una multiplicidad de voces en la arena pública, en el contexto de una sociedad democrática donde exista libertad de expresión (Cavalli 181). 
el resto del tejido colectivo de la sociedad, para así postular una imagen completa de la nación. Estas relaciones son siempre precarias y se ven interferidas por la ausencia el engaño y el desplazamiento físico, tres factores de dispersión que son efectos de la realidad política. En todos los casos se comprueba que el deseo de unidad y presencia está diferido o imposibilitado por una serie de barreras y prohibiciones que sitúan a los seres queridos en espacios irreconciliables. Parejas disueltas por la muerte, matrimonios minados por la infidelidad, hijos condenados a la orfandad, o migrantes que abandonan sus comunidades nativas: la imposibilidad de la reunión familiar rige la situación de los personajes de esta novela. ${ }^{5}$

Ocurre así en las relaciones de pareja, sean matrimonios o relaciones informales. Pese a que la pareja compuesta por Norma y Rey está legalizada por el matrimonio, desde un primer momento se ve amenazada por la incapacidad de procrear y por la identidad escindida de Rey, dos fantasmas internos que lo empujarán a mantener una relación ilegítima con Adela -unión que sí será fértil- y conducirán, por último, a la desaparición del personaje. La larga ausencia de este, que dura diez años, es aún más problemática y angustiosa, porque no viene acompañada de la certeza de su muerte. La memoria de Rey persiste en un interregno entre la vida y la muerte, entre la ausencia física y la esperanza de una reaparición: "For ten years, he had existed in memory, in that netherworld between death and life -despicably, sadistically called missing-and she had lived with the specter of him, had carried on as normal, as if he were away on an extended vacation and not disappeared and likely dead" (38). La indeterminación obstaculiza en Norma la realización del trabajo de duelo, razón por la cual el familiar perdido, su esposo ausente, se instala en su conciencia con una fuerza perturbadora que contradice la interdicción estatal de los nombres de los enemigos del régimen. El deseo melancólico de Norma y su nostalgia de un pasado feliz que, como llega a descubrir fue una ficción permitida por la duplicidad de Rey, determinan la condición espectral de esta pareja protagónica. Como veremos, la espectralidad es condición sintomática del funcionamiento de la memoria nacional.

Adicionalmente, la pareja de Norma y Rey está desestabilizada por la unión clandestina entre Rey y Adela, relación informal que corresponde a la faceta subversiva del profesor. Esta es una vinculación fugaz y esporádica, pautada por los viajes cortos de Rey a la selva, que no está sancionada por el amor-como sí ocurre entre Norma y Rey-,y cuyo único fruto es el nacimiento de Víctor. Queda claro que los desplazamientos físicos y las migraciones también resquebrajan a las familias y las comunidades, puesto

La penetrante observación de Edward Said sobre los problemas de la filiación en la literatura altomodernista se verifica en Lost City Radio (Said 17). Para Said, los problemas de filiación conducen, de manera lógica, a la creación de nuevas formas de asociación, es decir, de afiliación (Said 17). Sin embargo, en el mundo ficcional de Lost City Radio, parece ser que la fractura de la filiación no conduce la formación de nuevos esquemas solventes de afiliación.

172 Revista Iberoamericana, Vol. LXXIX, Núms. 244-245, Julio-Diciembre 2013, 1123-1139 ISSN 0034-9631 (Impreso) ISSN 2154-4794 (Electrónico) que es durante sus viajes a la selva cuando Rey engaña a Norma; análogamente, es al llegar a la capital cuando Víctor es abandonado por Manau. Sin embargo, aunque la muerte de Rey y Adela deja huérfano a Víctor, la tutela de Manau y la protección de Norma reconstruyen una informal y precaria familia nuclear. El profesor de escuela y la estrella de radio funcionan, hacia el final de la novela, como padres sustitutos del niño, pero, una vez más, su unión sólo puede ser pasajera y azarosa, un simulacro que está condenado a diluirse como las relaciones de pareja de todos los personajes.

Las relaciones entre padres e hijos pueden ser descritas en términos semejantes. Rey llega a conocer a su hijo Víctor, pero muere antes de que el niño aprenda a hablar. Adela fallece poco después, ahogada en el río. Norma no tiene hijos propios; la aparición de Víctor la enfrenta al problema de la maternidad, que para ella sólo puede ser temporal y postiza. Manau tampoco es padre, y, cuando Adela le encomienda a Víctor, el profesor de escuela lo abandona y huye al llegar a la ciudad capital. En 1797, las migraciones y los reclutamientos han mermado la población de hombres jóvenes. ${ }^{6}$ Muchos hijos se han ido, como es el caso de Nico, el mejor amigo de Víctor, que desaparece dejando solo a Zahir, su padre. En todos los casos, hijos y padres sólo pueden existir unos para otros desde la ausencia física, la distancia geográfica o la sustitución inestable. La relación entre Rey y su padre es una variante de la misma lógica: este almacena un resentimiento imborrable contra el hijo rebelde, cuyos ejercicios juveniles de subversión provocaron la expulsión de ambos de su pueblo natal en la sierra y la migración forzada a la ciudad. De forma correspondiente, la relación de Norma con sus progenitores está corroída por las constantes infidelidades del padre. También resulta significativo comprobar ciertas repeticiones inter-generacionales: Rey es profesor universitario, mientras que su padre fue director de escuela y, Manau, docente en 1797. La salida de Víctor de 1797 repite el destierro de su padre, quien a los trece años fue acusado injustamente de terrorista: en ambos casos, la política decreta los desplazamientos. Por último, la infidelidad de Rey es eco de la conducta del padre de Norma, que se identifica con su madre engañada.

La pretensión del Estado de intervenir en la memoria colectiva y en la historia nacional explica el funcionamiento precario de las relaciones entre esposos, entre amantes, entre padres e hijos. Un poder totalitario se impone verticalmente sobre los cuerpos de los ciudadanos victimizados, decretando la fractura afectiva de las parejas y la destrucción de las familias. Significativamente, la lógica que regula los vínculos entre el Estado y la ciudadanía es practicada, también, por el grupo subversivo IL, que institucionaliza una réplica del modelo estatal, a tal punto que es posible afirmar que sus respectivos modos de intervención en la sociedad son idénticos. Estos asuntos se

\footnotetext{
Éste es otro punto de contacto con la realidad histórica del Perú. Los niños y adolescentes fueron, durante los años del conflicto interno, duramente golpeados por la violencia política. Hablamos de víctimas directas e indirectas, pero también de menores de edad reclutados tanto por los grupos subversivos como por el estado para militar en la insurgencia y la contra-insurgencia (ver Toche 2010).
}

Revista Iberoamericana, Vol. LXXIX, Núms. 244-245, Julio-Diciembre 2013, 1123-1139 ISSN 0034-9631 (Impreso) ISSN 2154-4794 (Electrónico) 
convierten en objeto de reflexión para el único personaje de la novela que se aproxima a ser una figura intelectual: Rey, el profesor subversivo. ${ }^{7}$ En una serie de artículos publicados antes de su matrimonio con Norma, Rey describe un ritual que ha observado en la selva del país, llamado "tadek". El "tadek" es un sistema de justicia popular que se emplea para descubrir la identidad del culpable de algún delito (o, en realidad, para achacar la culpa a algún inocente). Las autoridades del pueblo seleccionan azarosamente a un niño, lo drogan con un té de hierbas y, bajo el efecto narcótico, lo instan a buscar al culpable, al que luego proceden a cortarle las manos. Rey sostiene que esta es una versión popular y folklórica de la justicia estatal en tiempos de guerra:

In measured prose, he applauded a few well-publicized cases of tortured union leaders and missing students as successful, contemporary versions of tadek, whereby the state assigned guilt based on outward signifiers (youth, occupation, social class) no more or less revealing than the geometric pattern of a woman's dress. (116)

La irónica crítica de Rey al sistema judicial no postula la inexistencia de los culpables -es decir, los subversivos-, sino la dificultad para distinguirlos del resto de la población, distinción que el Estado efectúa a través de una selección arbitraria sustentada en "significantes externos". Resulta significativo comprobar que el narrador en tercera persona define, en su sinopsis de la reflexión de Rey, cuáles son, específicamente, esos significantes externos, cuáles son las clases sociales, los sectores ocupacionales y los grupos generacionales que se convierten en blancos del "tadek" estatal: son líderes sindicales y estudiantes universitarios, es decir, grupos tradicionalmente asociados con posiciones ideológicas contestatarias. ${ }^{8}$ Cualquier miembro de estos grupos se convierte por su sola pertenencia a ellos, en un enemigo y en un culpable que debe ser castigado. Rey ataca la arbitrariedad del accionar del Estado, el cual actúa como una máquina ciega que, lejos de discriminar entre inocentes y culpables sobre la base de las conductas individuales, golpea a grupos enteros de la población. De esta manera, ejerce una violencia tan irracional y azarosa como la que propicia el niño drogado en el ritual tradicional. Esta definición de la justicia estatal se extiende al mismo IL, supuesto articulador de

Vale la pena aclarar que Rey no es un militante fanatizado por un dogma; sin dejar de ser crítico del Estado, su vinculación con IL presenta una ambivalencia continua que resulta reveladora del universo polifónico de la novela. No existe en ella una conciencia ético-política trascendente a los puntos de vista de los personajes, lo cual significa que tampoco existe una toma de partido a favor de ninguno de los bandos.

En algunos estudios sobre el síndrome de estrés postraumático (PTSD), se maneja la noción de que el trauma es un instrumento socio-político que se ejerce con precisión deliberada sobre ciertos grupos sociales marcados por una violencia institucional. Estos grupos se determinan en función de criterios raciales, socio-económicos, religiosos o de género (Tal 9). ISSN 0034-9631 (Impreso)

Vol. LXXIX, Núms. 244-245, Julio-Diciembre 2013, 1123-1139 ISSN 2154-4794 (Electrónico) las protestas sociales contra un régimen opresor, a través del caso de Zahir, el único personaje singularizado con un nombre propio que termina siendo víctima del "tadek".

Hombre público y respetado por su comunidad, Zahir es alcalde de 1797 durante la guerra interna. En este periodo de conmoción social, Zahir funge como espía de gobierno, encargado de escribir informes sobre cualquier personaje que pueda despertar sospechas. Entre ellos está Rey, que por entonces ya se ha involucrado con Adela y es asiduo visitante a 1797. Más allá del hecho de que Rey haya sido, en efecto, un colaborador de IL, la razón por la cual Zahir lo delata ante un funcionario estatal es antojadiza y arbitraria:

The next month, when Zahir travelled to the provincial capital to turn in his report, he brought with him, in a separate pocket, his description of Rey - three carefully edited pages in which Zahir noted the color of his skin, the shape of his smile, the timbre of his voice, and in which he had invented a story for the stranger to inhabit: the man was IL, a leader, a guerrilla. He had invented tire-burning, he murdered police officers for sport. Zahir transcribed a confession that had never taken place, and these sections of dialogue were, he was certain, the best writing he had ever done. (205-206)

La acusación es un invento dictado por la vocación fabuladora de Zahir, lo cual no niega que, en parte, sea exacta, aunque también muy exagerada. Años después de la escena aludida, una columna de IL llega a 1797 y conduce un "tadek" para determinar quién es el ladrón de unos víveres desaparecidos. El niño elegido es el mismo Víctor; oblicuamente justa, la sentencia recae en el delator Zahir, a quien le cortan ambas manos. No obstante, los subversivos jamás llegan a saber que Zahir había sido un agente del gobierno. Se ejecuta, así, una especie de justicia poética que discurre al margen de la arbitrariedad del Estado y de IL, dos instituciones gemelas que infligen análogas dosis de violencia irracional sobre la población civil. Al final de la novela, la muerte de Rey a manos de los soldados es fruto directo de la falsa acusación de Zahir; uno de sus captores le dice al profesor: "'You're famous', another voice said. 'You're thinner than I though you'd be. They say you plant bombs and kill cops. They say you invented tire-burning"' (255). Si el Estado no asesina a los ciudadanos por su pertenencia a un sindicato o una universidad, lo hace por suposiciones dudosas y acusaciones extra-judiciales.

Las fracturas de la filiación no son, pues, obra exclusiva del Estado, sino que comprometen también a su enemigo político en un juego especular. Por otra parte, estas fracturas encuentran correspondencia en la fragmentación del territorio nacional. La centralización política del país marca una clara diferencia entre la ciudad capital y las provincias, representadas sinecdóquicamente por 1797. La ciudad es una gran urbe moderna que se define por la velocidad, la congestión y la desigualdad. Como suele ocurrir en las ciudades latinoamericanas -y Lima no es la excepción-, también esta capital presenta un abigarrado cinturón urbano-marginal que es el resultado del flujo
Revista Iberoamericana, Vol. LXXIX, Núms. 244-245, Julio-Diciembre 2013, 1123-1139 ISSN 0034-9631 (Impreso) 
migratorio del interior. En Lost City Radio, el distrito de Tamoé está conformado por viviendas precarias que son, en su mayoría, producto de las invasiones de terrenos; será en este espacio donde tenga lugar el enfrentamiento decisivo entre las fuerzas del orden y los subversivos, en la famosa "Batalla de Tamoé". ${ }^{9}$ La sobrepoblación urbana contrasta con la fantasmagórica periferia nacional, que evidencia los efectos del despoblamiento. En tiempos de posguerra, los pobladores de 1797 son principalmente ancianos, mujeres y niños. Vacías y deshabitadas, las provincias son el origen de un masivo desplazamiento humano que, potenciado por la violencia política, ha generado la urbanización caótica de la capital. El producto de este proceso es metaforizado como un texto ilegible en virtud de su tamaño desproporcionado y su dinamismo incontrolable: "The city was an unknowable thing, sprawling and impenetrably dense" (72). Esta monstruosa realidad urbana es el escenario donde se desarrolla el drama de la disolución familiar. Fragmentada y heterogénea, la población urbana es una acumulación de individuos solitarios y desarraigados. Su sentido de pertenencia se vincula nostálgicamente con una estructura ausente: la cohesión entre los parientes, que perdura fantasmáticamente en la memoria

Por ello no resulta extraño encontrar imágenes contrapuestas de la urbe, que aparece representada bien como una opresiva realidad de aglomeraciones multitudinarias, o bien como un espacio vacío, habitado únicamente por la ausencia. En ciertas escenas el modo de representación realista se ve interferido por otro régimen, dentro del cual la fisonomía material de la ciudad acoge la proyección de la psicología individual o del deseo colectivo. Lo primero ocurre en el capítulo dos, cuando Norma y Víctor se encuentran rodeados por una turba de ciudadanos, masa agresiva y monstruosa, que les exigen apuntar los nombres de sus desaparecidos para luego ser leídos al aire: "There was noise, shouting, an engine backfiring. The crowd swelled. It was impossible to tell how many people there were, or where they had come from. They towered over Victor and blotted out the sky" (33-34). Después de desembarazarse de la multitud, Norma y Víctor logran huir y se enfrentan a una visión radicalmente distinta: "[...] they had emerged in a wide, desolate plaza graced with palm trees, lit by orange streetlamps"(34) La plaza desierta y la masa compacta son los dos polos de una vida urbana que, como Norma le explica a Víctor, está directamente afectada por la intromisión del estado a través del toque de queda, introducido después de la guerra: "It was night, Norma told him, and the city lived indoors at these hours" (34). En esta alternancia radical entre la ausencia y la presencia, la representación de la ciudad materializa el vacío y la soledad

\footnotetext{
La importancia de las zonas urbano-marginales como centro estratégico de la guerra interna es un elemento que el mundo representado y la realidad peruana comparten. Tamoé podría ser una image refractada del distrito limeño de Villa El Salvador, que fue clave en la guerra entre el Estado y Sender (Burt 269). Además, el hecho de que Rey haya trabajado para una agencia gubernamental dedicada a la titulación de terrenos no parece ser azaroso, ya que esta fue una de las estrategias proselitistas puestas en
} práctica por Sendero Luminoso en Villa El Salvador (Burt 283).

17. Revista Iberoamericana, Vol. LXXIX, Núms. 244-245, Julio-Diciembre 2013, 1123-1139 ISSN 0034-9631 (Impreso) ISSN 2154-4794 (Electrónico) que experimentan los capitalinos, habitantes de un espacio sobrepoblado y solitario a la vez. Canaliza, además, una añoranza social, el mismo deseo de restitución de la presencia que justifica esa popularidad rayana en la sacralización que disfruta el show radial "Lost City Radio".

Lo vacío, lo inmóvil y lo estéril son las coordenadas que describen los espacios privados, los cuales también están contaminados por la misma atmósfera espectral. E departamento de Norma es un reducido espacio de dos habitaciones que ella habita sola, sin admitir otra presencia viva: "A sealed place, an impregnable store of memories where time had stopped for nearly a decade. Visitors? She could count them on her fingers. Without Rey, she had lived like this: spectacularly alone" (49). Esta soledad es "espectacular" en dos sentidos: primero, porque es extrema, pero además, porque se exhibe como visible en tanto que nace de lo privado y transita hacia lo público. El almacén de memorias es también el repositorio de un erotismo perdido, del contacto placentero con el cuerpo del ausente. La visión del amante es un dato capital: Norma ya no puede ver a Rey, y, en este trance, también el cuerpo de la mujer pierde consistencia, se diluye y se invisibiliza. A consecuencia de la falta de Rey, también Norma sufre una espectralización. Incapaz de reentablar relaciones sentimentales con otros, todos sus afectos giran en torno al ausente. Esta intervención de la pérdida en su subjetividad es radical y prolongada, y se materializa en el espacio de su departamento, proyección materializada de una biografía que merece calificativos análogos a los de su residencia: "Her private life was antiseptic and empty, a place for memory, music, and solitude" (61). La espectralidad reinante en su vida y en sus espacios remite a una conducta patológica estudiada por Freud: la del sujeto incapaz de culminar exitosamente el trabajo de duelo (Trauerarbeit), que se prolonga indefinidamente. ${ }^{10}$

El ejemplo de Norma se difunde en la totalidad de un mundo representado que, tal vez, tenga una de sus pocas instancias de armonía y congregación en la radio. Instalada en el centro vacío de su vida privada, la existencia de Norma se descorporaliza para residir, con mayor intensidad que en ningún otro ámbito, en un dominio público donde sólo se manifiesta como voz radial. Ahora bien, es preciso recordar que la radio suele estar asociada con una "calidad de inmediatez y de autoridad" (Birkenmaier 690) que, a través de la conexión afectiva que establece entre el locutory el oyente, genera una ilusión de presencia y un simulacro de intimidad que el carácter masivo del medio desmiente.

${ }^{10}$ Dice Freud sobre el duelo (Trauer) en "Mourning and Melancholia" (1915): "Mourning is regularly the reaction to the loss of a loved person, or to the loss of some abstraction which has taken the place of one, such as one's country, liberty, an ideal, and so on [...] Profound mourning, the reaction to the loss of someone who is loved, contains the same [comparado con la melancolía] painful frame of mind, the same loss of interest in the outside world -in so far as it does not recall him-the same loss of capacity to adopt any new object of love (which would mean replacing him) and the same turning away from any activity that is not connected with thoughts of him" (Freud 244) ISSN 0034-9631 (Impreso) ISSN 2154-4794 (Electrónico) 
Paul Deharme, un téorico de la radio de la década de 1930, señaló la analogía existente entre la voz del locutor y la del psicoanalista, atribuyéndole una dinámica terapéutica a la relación del radioescucha con las ondas radiales que se instalan en el hogar moderno (Birkenmaier 696). ${ }^{11}$ Por su parte, Rudolph Arnheim planteó la superioridad de la radio sobre la prensa, en virtud de la primera para adquirir una potente inmediatez y un actualidad corporal (Birkenmaier 696). Además, la facilidad con que la radio puede alcanzar los rincones más alejados de la nación, y enlazar así regiones y poblaciones diversas, da cuenta de la importancia de este medio para generar espacios de cohesión colectiva durante el proceso de modernización de América Latina (Birkenmaier 694) En el programa "Lost City Radio", la fantasía de una "presencia afectiva" radial se torna, dadas las circunstancias políticas, especialmente intensa en su interpelación del oyente; se trata, sin embargo, de una fantasía defraudada. No sólo está la ilusión de presencia puesta en entredicho, sino que el supuesto valor terapéutico de la radio se ve reemplazado por la anti-terapéutica prolongación del trauma. El resultado de esta negatividad de la voz radial es la constatación de una fragmentación irremediable de la comunidad y de la subjetividad. ${ }^{12}$

Las ondas sonoras constituyen el medio donde la biografía de Norma se despliega y se transfigura en voz. Su voz aparece, además, como el continente de una sucesión de nombres, una legión de ausentes. Con estos nombres la locutora mantiene una relación simbólica de maternidad, que sella una alianza entre el ámbito público y la esfera privada: "Her public life was the radio, where she was mother to an imaginary nation of missing people"(61). En otras palabras, la voz pública y descorporalizada de Norma constituye el receptáculo materno en el cual anida un territorio imaginario por el que desfila un segundo país de nombres sin cuerpo, de significantes cuyos referentes orgánicos están ausentes. Sin embargo, la voz de Norma no debe ser interpretada como el ámbito de la reposición exitosa de los desaparecidos, porque entraña una capa adicional de espectralidad: entre los nombres leídos por Norma, no figuran los de aquellos que han sido proscritos por

\footnotetext{
"A partir de la lectura de La tía Julia y el escribidor de Mario Vargas Llosa, Anke Birkenmaier estudia las relaciones entre la radio y el surrealismo. Resulta interesante leer su análisis de la relación entre radio e inconsciente: "La radio como medio puramente aural ayuda a reforzar el sentido de una realidad que proviene del inconsciente y por ello aparece como super-real. La voz radial tiene la misma calidad de inmediatez y autoridad como antes las voces oídas por los inspirados, o las de los muertos por los médiums" (690). Es posible argumentar que la voz de Norma se dirige no a la parte racional del yo del . acio donde se aloja el rauma.

${ }^{12}$ Un tratamiento cercano del rol de la radio en la sociedad, definido por la ineficacia, puede encontrarse en otra novela peruana reciente: El fondo de las aguas (2006) de Peter Elmore. En esta novela, la radio tampoco sirve para crear una comunidad de oyentes, sino para hacer visible la soledad y aislamiento de
} los que la escuchan. el gobierno. Sus dueños han sufrido una doble borradura, física y simbólica, que los excluye radicalmente del espacio nacional y los torna impronunciables, irrecuperables. La nación que la voz de Norma pone en escena es una nación incompleta, desgarrada por la gestión estatal de la memoria. Por ello el éxito mediático de "Lost City Radio" es inversamente proporcional a su eficacia real. Los medios de comunicación controlados por el Estado ofrecen una ilusoria promesa de reconciliación que el mismo Estado ha declarado impracticable. ${ }^{13}$ Por más que, hacia el final de la novela, Norma decida transgredir la censura estatal y leer al aire el nombre prohibido de Rey, este aparece representado como un gesto de rebeldía inútil después de la muerte física del profesor, que ha ocurrido tiempo atrás. El gesto no parece entrañar un beneficio terapéutico para Norma, como tampoco lo ofrece "Lost City Radio" para sus oyentes.

Cabe preguntarse, llegados a este punto, cómo describir la forma de pertenencia que vincula a estos sujetos, háblese de Norma o de sus miles de fanáticos, con la nación que los engloba en tanto con-ciudadanos. Parece ser que la filiación postraumática, esa filiación entre personas y fantasmas, entre presentes y ausentes, se presenta como el emblema de un modo generalizado de existir en la comunidad. Se trata de un modo de interactuar con el otro a nivel cívico y simbólico que transita por la dimensión privada de la afectividad, y que, en términos de Terry Eagleton, evidencia una estetización de las relaciones sociales y políticas: su inscripción en el cuerpo. ${ }^{14}$ En Lost City Radio, es posible rastrear en los cuerpos de los seres ficcionales un impulso "estético" espontáneo que explica la pertenencia visceral e instintiva del sujeto a la nación: dicho impulso es el trauma, en tanto cifra de la relación con lo ausente. Se trata, ciertamente, de una fuerza negativa y dolorosa para quienes la experimentan. Por obra del trauma, que rige y quiebra los esquemas de filiación, la experiencia de existir en la nación se traduce a una experiencia permanente de malestar; a un tráfico diario con espectros. ${ }^{15}$

${ }_{13}$ Al respecto afirma Gustavo Faverón: "Pero, en ese caos, en el que todo viejo lazo familiar o comunal ha sido triturado, todo el mundo es, para alguien, un desaparecido: el programa resulta entonces un símbolo de la reconciliación pero también de la dificultad de la reconciliación y de la memoria en un universo que vive, una vez más, a oscuras, o, en el mejor de los casos, bajo la luz torva de una vela mentirosa: la opresión autoritaria" ("En busca de la ciudad perdida" 2006)

14 "The ultimate binding force of the bourgeois social order, in contrast to the coercive apparatus of absolutism, will be habits, pieties, sentiments and affections. And this is equivalent to saying that power in such an order has become aestheticized It is at one with the body's spontaneous impulses, entwined with sensibility and the affections, lived out in unreflective custom. Power is now inscribed in the accordingly healed" (Eagleton 20).

${ }^{15}$ En este punto, Lost City Radio se acerca a una novela peruana reciente: Un lugar llamado Oreja de Perro de Iván Thays (2008). Esta lidia también con la representación de las secuelas de la guerra interna entre Sendero Luminoso y el Estado peruano. Como paralelo central entre los textos de Alarcón y Thays puede señalarse la presencia de un personaje protagónico que se enfrenta a una tragedia de envergadura nacional

(1) $\frac{\text { Revista Iberoamericana, Vol. LXXIX, Núms. 244-245, Julio-Diciembre 2013, 1123-1139 }}{\text { ISSN 0034-9631 (Impreso) }}$
(1.7) $\frac{\text { Revista Iberoamericana, Vol. LXXIX, Núms. 244-245, Julio-Diciembre 2013, 1123-1139 }}{\text { ISSN 0034-9631 (Impreso) }}$

(1.7) $\frac{\text { Revista Iberoamericana, Vol. LXXIX, Núms. 244-245, Julio-Diciembre 2013, 1123-1139 }}{\text { ISSN 0034-9631 (Impreso) }}$
Revista Iberoamericana, Vol. LXXIX, Núms. 244-245, Julio-Diciembre 2013, 1123-1139 ISSN 0034-9631 (Impreso) ISSN 2154-4794 (Electrónico) 
La voz de Norma ofrece el lugar donde se manifiesta el malestar de una nación fantasmagórica, que representa un doble simulacro: por una parte, una gran cantidad de los nombres que ella pronuncia están irremediablemente separados de los cuerpos, puesto que estos pertenecen a los asesinados por el Estado o por IL. Además de ello, los signos que jamás serán publicados sufren un grado aún más extremo de abstracción y distanciamiento. Claro está, el silencio público no disminuye la persistencia de los nombres ilegales en la memoria de los sobrevivientes. El obstáculo se halla en el tránsito de la memoria privada a la memoria colectiva, tránsito que ha sido monopolizado y bloqueado por el Estado. La memoria colectiva se construye a través de la narración que permite exteriorizar, en el ámbito público, los contenidos del conjunto de las memorias privadas. El hecho de que la narración no sea posible, o que haya sido asumida directamente por el poder, permite que los eventos acallados sigan cumpliendo un papel en la construcción de una memoria informal y alternativa. ${ }^{16}$

Finalmente, esta incapacidad para decir los nombres prohibidos de quienes, realmente, no pueden ser olvidados, pone en escena la irresolución del trabajo de duelo, que asume una escala nacional. Dentro de un proyecto institucional de gestión y reescritura de la memoria nacional, los eventos traumáticos de la guerra civil han sido silenciados y excluidos de la historia, pero estos hechos y los nombres de los desaparecidos emergen e irrumpen, " $[\ldots]$ putting people in a situation in which they cannot remember and they cannot forget" (Marques, Paez, Serra 257). En un universo distópico que no ofrece salidas ni consuelos, la prolongación indefinida del duelo es la premisa irremediable de una realidad en la cual el fracaso del proyecto nacional -es decir, la ruptura del pacto entre la sociedad civil y el estado-, ha decretado la cancelación del devenir histórico y el encierro en el círculo vicioso de una memoria dolorosa. El plano individual donde los personajes de Lost City Radio experimentan el dolor de la perdida produce, por efecto de acumulación simbólica, una dimensión colectiva en la que se conforma una nación escindida entre la historia oficial y la memoria informal, entre una ciudadanía visible y una población fantasmagórica. Los sobrevivientes de la guerra no constituyen una comunidad. Son sujetos alienados y dislocados cuyos cuerpos señalados por el trauma forman una muchedumbre urbana, una masa caótica y quebrada que, en sus desplazamientos por la capital monstruosa, oculta un deseo melancólico. El objeto de deseo perdido es, por una parte, el ser querido, el hijo lejano, la pareja ausente o el familiar asesinado; no obstante, el duelo es también abstracto y colectivo. En el plano

desde el dolor privado, dolor que le otorga un privilegio epistemológico para indagar en la problemática nacional. Ver Elmore 2009.

16 "Collective silence and dismissing the role of society as a whole ends up by reinforcing the strength of both individual and collective level informal memories. As a result, what appears on the surface to be institutional forgetting and silence actually corresponds to hidden rumination and suffering" (Marques, Paez, Serra 257).

Revista Iberoamericana, Vol. LXXIX, Núms. 244-245, Julio-Diciembre 2013, 1123-1139 ISSN 0034-9631 (Impreso) ISSN 2154-4794 (Electrónico) de la imaginación nacional, el objeto cuya reposición se reclama inútilmente es una versión idílica de la nación misma: una comunidad orgánica y armónica, una sociedad democrática e igualitaria, en cuyo seno la libertad del individuo es posible, y donde los lazos familiares y los vínculos amorosos no encuentran obstáculos para florecer.

Planteaba, páginas atrás, que el concepto de alegoría puede sernos útil para entender las relaciones entre lo individual y lo colectivo en Lost City Radio. En su lectura eróticopolítica de la novelística latinoamericana del siglo XIX, Doris Sommer sostiene que la escritura de novelas estuvo ligada al proyecto nacionalista de las élites liberales. Así, los llamados romances fundacionales, novelas instrumentales a la construcción de la nación, entrañan una intensa articulación alegórica entre el deseo y la política: la pareja heterosexual que suele protagonizar estas novelas, la dupla hombre-mujer unida por el lazo matrimonial, se convierte en el núcleo alegórico dentro del cual convergen, negocian y pactan personajes heterogéneos y representativos de diferentes regiones, sectores económicos, estratos sociales y orígenes étnicos (Foundational Fictions). De esta manera el matrimonio, lugar por excelencia del amor y el entendimiento mutuo, se convierte en la imagen deseable de la nación unida que se desea construir. Ahora bien, aunque considero que sería inadecuado -y por cierto anacrónico- describir como alegóricas, en el sentido que Sommer atribuye al término, las relaciones que, en Lost City Radio, se entablan entre los afectos y la política, parece ser que la naturaleza del objeto perdido, el objeto de ese duelo abstracto y colectivo mencionado antes, encierra un factor que lo emparienta con el viejo proyecto del romance fundacional decimonónico. Ese factor viene a ser la cohesión erótico-familiar, la fortaleza orgánica del núcleo familiar y de las parejas, cohesión y fortaleza que se erigen como índice representativo del modelo nacional que se añora, porque no se posee. De esta manera, una novela escrita en los primeros años del siglo xxi diseña un modelo de nación ideal apelando, como hacían los romances fundacionales, a la alegoría del matrimonio y de la familia como el crisol donde lo heterogéneo alcanza una conciliación. Sin embargo, hay una diferencia clave: en el siglo XIX, se trataba de crear una nación donde esta no existía; en Lost City Radio, la nación ideal constituye un objeto añorado, un emblema de perfección que contrasta radical y dolorosamente con un presente lleno de imperfecciones: el de la nación quebrada por varias formas de violencia. De todos modos, el conocimiento de dichas imperfecciones constituye un paso necesario para diseñar un mejor futuro.
Revista Iberoamericana, Vol. LXXIX, Núms. 244-245, Julio-Diciembre 2013, 1123-1139 ISSN 0034-9631 (Impreso) 


\section{OBRAS CONSULTADAS}

Alarcón, Daniel. Lost City Radio. New York: Harper Collins Publishers, 2007. Radio ciudad perdida. Lima: Alfaguara, 2007.

War By Candlelight. New York: Harper Collins Publishers, 2005. Guerra a la luz de las velas. Lima: Alfaguara, 2006.

Benjamin, Walter. “What is Epic Theater?”. Illuminations. Harry Zohn, trad. New York: Schocken Books, 2007. 147-154.

Birkenmaier, Anke. "Transparencia del subconsciente: escritura automática, melodrama y radio en La tía Julia y el escribidor". Revista iberoamericana LXXIV/224 (JulioSeptiembre 2008): 685-701.

Burt, Jo-Marie. "Shining Path and the 'Decisive Battle' in Lima's Barriadas: The Case of Villa El Salvador". Shining and Other Paths. War and Society in Peru, 19801995. Steve J. Stern, ed. Durham: Duke UP, 1998. 267-306.

Cavalli, Alessandro. "Reconstructing Memory After Catastrophe. How Memory is Reconstructed after Catastrophic Events". Meaning and Representation in History. Jörn Rüsen, ed. New York: Berghahn Books, 2006. 169-182.

Davies, Laurence. "At Play in the Fields of Our Ford: Utopian Dystopianism in Atwood, Huxley and Zamyatin". Transformations of Utopia. Changing Views of the Perfect Society. George Slusser, Paul Alkon, Roger Gaillard, y Danièle Chatelain, eds. New York: AMS Press, 1999. 205-214.

Eagleton, Terry. The Ideology of the Aesthetics. Oxford: Basil Blackwell, 1990.

Elmore, Peter. El fondo de las aguas. Lima: Peisa, 2006.

"El viaje al interior". Hueso Húmero 53 (2009): 212-217.

Faverón, Gustavo. "En busca de la ciudad perdida. Los cuentos de Daniel Alarcón y su próxima novela". Revista Somos. Diario "El Comercio", (Lima: 10 de diciembre de 2006).

ed. Toda la sangre. Antología de cuentos peruanos sobre la violencia política. Lima: Editorial Matalamanga, 2006.

Freud, Sigmund. "Mourning and Melancholia". The Standard Edition of the Complete Psychological Works of Sigmund Freud. James Stratchey, trad. y ed. Vol. XIV (1914-1916): 237-258.

Lukács, Georg. Problemas del realismo. México: Fondo de Cultura Económica, 1996

Marques, Jose; Dario Paez; Alexandra F. Serra. "Social Sharing, Emotional Climate, and the Transgenerational Transmission of Memories: the Portuguese Colonial War". Collective Memory of Political Events: Social Psychological Perspectives. James W. Pennebaker, Dario Paez y Bernard Rimé, eds. Mahwah: Lawrence Erlbaum Associates, 1997.

Mauceri, Philip. "An Authoritarian Presidency: How and Why Did Presidential Power Run Amok in Fujimori's Perú?". The Fujimori Legacy. The Rise of Electoral

4. Revista Iberoamericana, Vol. LXXIX, Núms. 244-245, Julio-Diciembre 2013, 1123-1139 ISSN 0034-9631 (Impreso) ISSN 2154-4794 (Electrónico)
Authoritarianism in Peru. Julio F. Carrión, ed. University Park: Pennsylvania State UP, 2006. 39-60.

McClintock, Cynthia. "Electoral Authoritarian Versus Partially Democratic Regimes: The Case of the Fujimori Government and the 2000 Elections". The Fujimori Legacy. The Rise of Electoral Authoritarianism in Peru. Julio F. Carrión, ed. University Park: Pennsylvania State UP, 2006. 242-267.

Plattel, Martin G. Utopian and Critical Thinking. Pittsburgh: Duquesne UP, 1972.

Richter, Peyton E. "Utopia/Dystopia?: Threats of Hell or Hopes of Paradise". Utopia/ Dystopia? Peyton E. Richter, ed. Cambridge: Schenkman Publishing Company, 1975. 1-28.

Said, Edward. The World, the Text and the Critic. Cambridge: Harvard UP, 1983.

Sommer, Doris. Foundational Fictions. The National Romances of Latin America. Berkeley: U of California P, 1991.

Tal, Kalí. Worlds of Hurt. Reading the Literatures of Trauma. Cambridge: Cambridge UP, 1996

Thays, Iván. Un lugar llamado Oreja de Perro. Barcelona: Anagrama, 2008.

Toche, Eduardo. "Los niños de la guerra”. Revista Quehacer 180 (Octubre-Diciembre 2010): 78-85.

Tonkin, Boyd. "Boyd Tonkin: A Week in Books". The Independent. 18 May 2007. $<$ http://www.independent.co.uk>. 13 junio 2011.

Yushimito, Carlos. "Emigración: un tema postergado. Anotaciones a propósito de Guerra a la luz de las velas de Daniel Alarcón”. 2006. <http://www.letras.s5.com/ da241006.htm>. 13 junio 2011
Revista Iberoamericana, Vol. LXXIX, Núms. 244-245, Julio-Diciembre 2013, 1123-1139 ISSN 0034-9631 (Impreso) 
